\title{
Model for the approximate assessment of nitrogen content in swollen reduced iron ore from single measurements
}

\author{
Oscar Dam G. \\ ORCID: https://orcid.org/0000-0002-0594-6757 \\ oscar.curmetals@gmail.com \\ UNEXPO Puerto Ordaz \\ Fellow- International Iron Metallics Association \\ (IIMA) \\ Puerto Ordaz-Venezuela
}

Recibido (08/02/21), Aceptado (18/02/21)

\begin{abstract}
A method of calculation has been derived to assess the nitrogen estimated content in iron reduced samples. The method is based on the review of observations and laboratory measurements of relationships between the rate of reduction and the corresponding metallic iron formation during the reduction process. The metallic iron formation has been calculated from relationships that apply to a wide variety of types of ores undergoing reduction under a nitrogen-containing gas mixture in proportions above $50 \%$ by volume. The empirical correlations found between the rates of metallization, the sample swelling index, and the equilibrium nitrogen solubility in iron can be used for determined the approximate final content of nitrogen in the reduced samples from the estimated and measured final volume of the reduced specimens. It is necessary to have an accurate analysis of the starting sample as well as the reducibility information.
\end{abstract}

Keywords: Iron ore, nitriding, catastrophic swelling, rate of metallization, reduction degree

\section{Modelo para la evaluación aproximada del contenido de nitrógeno en mineral de hierro reducido hinchado a partir de mediciones únicas}

Resumen: Se presenta un método de cálculo concebido para estimar el contenido de nitrógeno disuelto en muestras hierro de reducido. El método se basa la reinterpretación de las observaciones y medida de las relaciones entre la velocidad de reducción y el correspondiente hierro metálico formado durante el proceso de reducción. La formación de hierro metálico ha sido calculada a partir de relaciones que aplican a una gran variedad de tipos de mineral de hierro reducidos con gases reductores que contienen más de un $50 \%$ en volumen de nitrógeno. Las correlaciones empíricas encontradas entre la velocidad de metalización, el índice de hinchamiento de las muestras y la solubilidad en equilibrio de nitrógeno en hierro pueden ser utilizadas para determinar en forma aproximada el contenido de nitrógeno en las muestras reducidas a partir de la medición final del volumen de la muestra reducida. Para el uso del modelo desarrollado es necesario disponer del análisis inicial preciso de la muestra, así como de los datos de la reducibilidad de la misma.

Palabras Clave: Óxidos de hierro, nitruración, hinchamiento catastrófico, velocidad de metalización, grado de reducción 


\section{I.Introduction}

The catastrophic swelling of iron oxides undergoing reduction with gas mixtures containing nitrogen gas in proportions higher than $0.5 \%$ in volume, has been studied at different temperature levels but has not considered the influence of the nitriding of the freshly formed iron in the magnetite-Wustite reduction step. Recently a close approach to this effect has been undertaken to assess the correlation and effect of the nitrogen absorption rate on the rate of increase of the iron oxide volume while the formation of iron increases. The model presented below is based on the review and reinterpretations of laboratory observations and measurements of empirical relationships between the rate of reduction and the corresponding metallic iron formation during the reduction process. The iron formation has been calculated from relationships that apply to a wide variety of types of ores undergoing reduction under nitrogen-containing gas mixtures in proportions above $50 \%$ by volume [1]. The validity of the model has been tested by comparing its calculated values with those obtained in reducibility laboratory tests and by determining the reduced iron sample during the reduction path by using the method determined by Dam and Jeffes [2], which was tested by comparing it with analytical chemistry results showing a $3 \%$ error between the actual and computed results analytical errors, which compares with the sampling and analytical errors.

\section{II.Experimental data}

The basic data used in this paper was taken from reference [4] related with hydrogen and carbon monoxide in the order of $30 \%$ as the reducing gas and $70 \%$ nitrogen gas, and the variables were chosen were the reducibility curves from which the mathematical method described [5] allowed the assessment of the following variables a) metallic iron content, b) the rate of metallic iron formation and c) the swelling index for measuring the sample volume increase all along the reduction path.

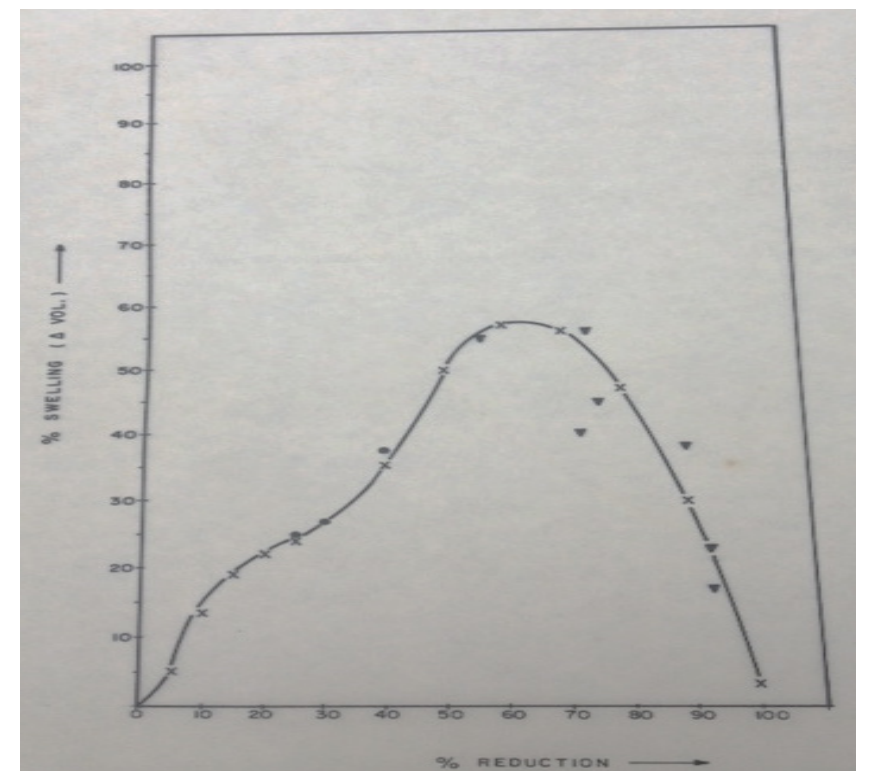

Fig. 1. Catastrophic swelling of reduced iron oxide samples undergoing reduction with $30 \% \mathrm{H} 2 / 70 \% \mathrm{~N} 2$ and $30 \% \mathrm{Co} / 70 \% \mathrm{~N} 2$ at $900{ }^{` C}[1]$.

The mathematical expression of the curve shown in Figure I once the reduction degree is converted to (dFe/ $\mathrm{dt})$ at $30 \%$ reduction, is as follows

$$
\begin{aligned}
& \Delta \% \text { Volume }=(22.9579+72.5247 * \mathrm{PN} 2) * \operatorname{EXP}(-\mathrm{b} *(\mathrm{dFe} / \mathrm{dt}) 30 \%) \\
& \mathrm{b}(\min / \%)=-0.1071 * \mathrm{PN} 2-0.0115
\end{aligned}
$$

Where PN2 is the partial pressure of nitrogen in the reducing gas mixture expressed in a fraction of it, b 
is a constant for each nitrogen content in the gas mixture, and $(\mathrm{dFe} / \mathrm{dt}))$ is the rate of metallization measure at $30 \%$ reduction. From the corresponding graphic, it was possible to obtain the following data a) relationship between the nitrogen content and the reduced iron sample, b) the rate of the volume increase and the reduction temperature. The first correlation was discussed by Dam [5] and show for follow-up purposes in Figure 2, the second correlation was derived from a similar curve described by Agarwal [7], as shown in Figure III in the data analysis section.

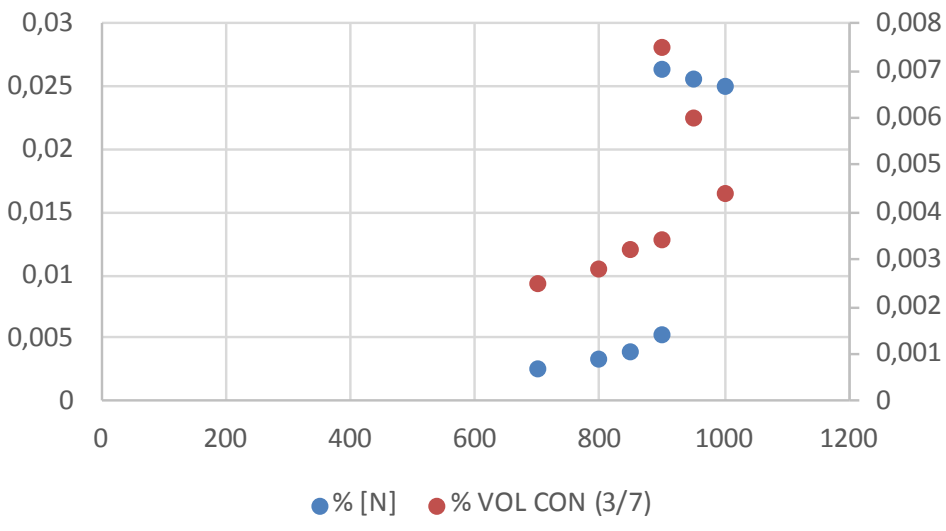

Fig. 2. Nitrogen content (\% y axis left) relationship with the reducing temperature $(\mathrm{x}$ axis) $\mathrm{y}$ and the volume increase of the reduced iron simple (\%/1000, y axis right), reducing gas $30 \% \mathrm{CO} / 70 \% \mathrm{~N} 2$ (Source author [3])

\section{III.Data analysis}

The available data [6] was gathered around the achieved reduction degree at a given time, the metallic iron content at the before mentioned reduction degrees and time the measured volume increase of the sample at the selected percent reduction and time when reducing gas, hydrogen, or carbon monoxide, containing $70 \%$ nitrogen by volume at 900 degrees Celsius for the ammonia gas case and 970 degrees Celsius for the case of the use of Indian coals containing nitrogen in the form of ammonia. The conversion of the data from Fig. 1 is shown in Table 1, in this table it is shown the different types of reduction kinetics as shown in Fig. 4, which mathematical expression for the curve shown below in equation 3 for the gas reducing mixture $30 \% \mathrm{H} 2 / 70 \% \mathrm{~N} 2$.

$$
\% \mathrm{Vol}=-0.2333 \mathrm{t}^{2}+8.4435 \mathrm{t}-20.436
$$

Table 1. Reduction time min

\begin{tabular}{|l|l|l|l|l|l|l|l|l|l|l|l|l|l|l|}
\hline Reduction time min & 2 & 5 & 6 & 7 & 8 & 10 & 12 & 14 & 18 & 25 & 30 & 45 & 60 & 90 \\
\hline \%Vol.30\%H2/70\%N2.900 `C & 5 & 10 & 18 & 23 & 28 & 45 & 49 & 59 & 57 & 47 & & & & \\
\hline \%Vol Coal 970 ` & 1 & & & & & & & 16.1 & & & 16,5 & 16,7 & 17,5 & 15.8 \\
\hline
\end{tabular}




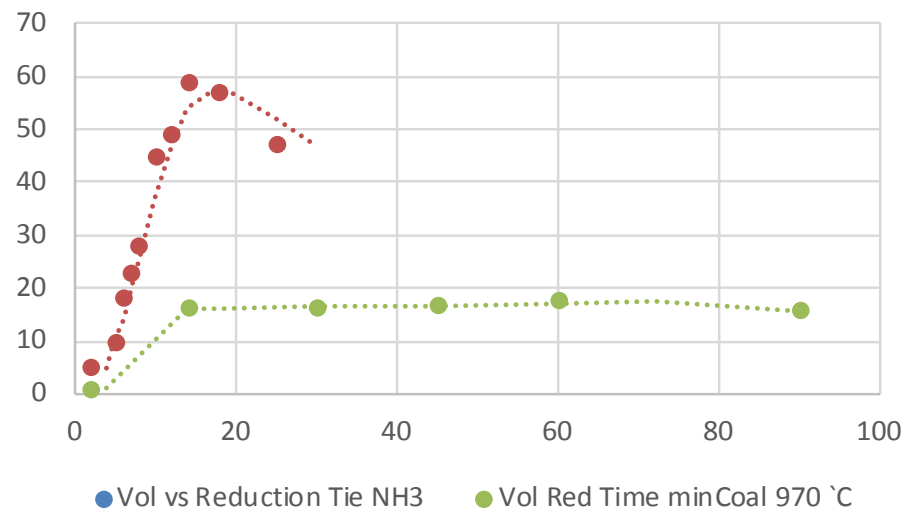

Fig. 3. \%Volume increase as a function of the reduction time (min). (Source the author)

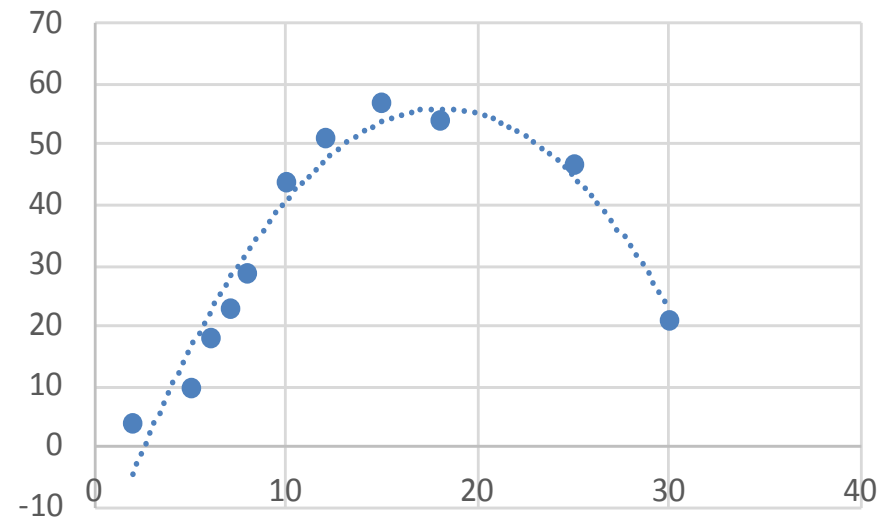

Fig. 4. Rate of \% volume increase (swelling) as a function of the reduction time (min) for 30\% $\mathrm{H} 2 / \mathrm{CO}$ and $70 \%$ N2 reducing gases. (Source. Author).

The empirical mathematical expression for estimation of the swelling index (\%Vol.) as shown in Figure 5 is expressed as follows

$$
(\% \mathrm{Vol})=-0.2333 \mathrm{t}^{2}+8.4435 \mathrm{t}-20.436
$$

The combination of the relationships shown between the reduction time, the metallic iron formation, the volume increase with the unstable equilibrium nitrogen solubility taken from the FeN diagram, is ten possible to estimate the nitrogen absorbed by reduced iron as the oxide reduction takes place under certain conditions which are from $0,5 \%$ by volume upwards in the reducing mixture. Fig. 5 is shown the relationship between the volume increase and the estimated nitrogen dissolved in the reduced iron expressed as $[\% \mathrm{~N}]$. The results show in Table 2 , are consistent with the results shown in Figure II, obtained from the following mathematical expression (5).

Table 2. Nitrogen dissolved in reduced iron [N] versus an increase of sample volume

\begin{tabular}{|c|c|l|c|c|c|}
\hline$\%$ Vol. & 28 & 32 & 75 & 80 & 44 \\
\hline$\%[N]$ & 0,003 & 0,004 & 0,005 & 0,0263 & 0,025 \\
& 3 & 0 & 3 & & 6 \\
\hline
\end{tabular}


The relationship found between the swelling index (\% Volume) and the dissolved nitrogen $[\% \mathrm{~N}]$ in the metallic iron in the reduced sample, will allow the calculation of the iron lattice stress distortion and further effects and represented by the following mathematical equation 5 .

$$
\% \mathrm{~N}]=-5 \mathrm{E}-05(\% \mathrm{Vol})^{2}+0.0048(\% \mathrm{Vol})-0.0989
$$

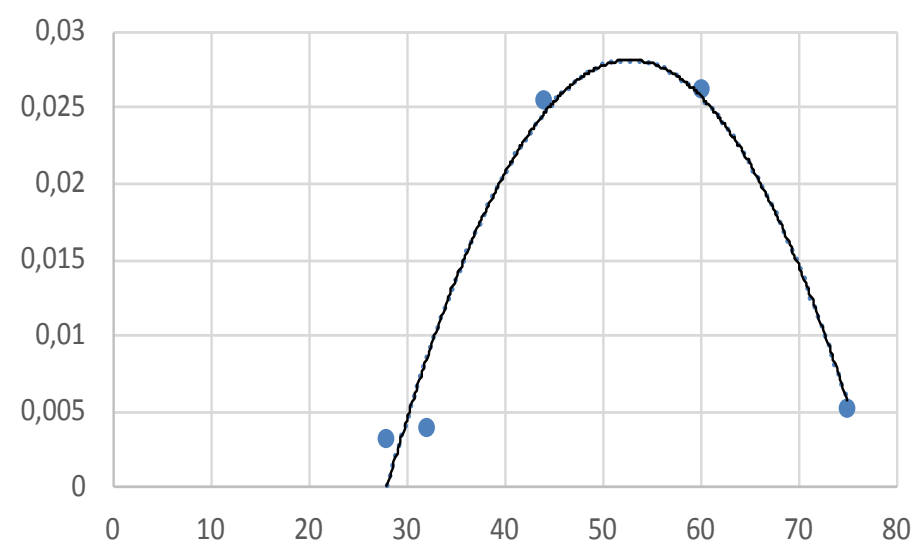

Fig. 5. Relationship between the reduced iron \% volume expansion ( $\mathrm{x}$ axis) with the dissolved nitrogen (\%) in fresh metallic iron produced.

\section{IV.The calculation method}

For the estimation of the amount of dissolved nitrogen in reduced iron the following calculation steps

a.Based on the initial analytical analysis of the sample, and from the continuous reduction curve calculate the $\%$ reduction, and the specific reduction velocity known as

$(\mathrm{d} \% \mathrm{R} / \mathrm{dt}) 40 \%=33.6 / * \mathrm{t} 30 \% \mathrm{R}-\mathrm{t} 60 \% \mathrm{R}) \quad($ expressed in $1 / \mathrm{min}$ )

Where $\mathrm{T} 30 \% \mathrm{R}=$ time for $30 \%$ reduction, and $\mathrm{t} 60 \% \mathrm{R}=$ time for $60 \%$ reduction

b.Once the $\%$ reduction $(\% \mathrm{R})$, is calculated, proceed to calculate $\%$ Metallization, using equation 6 [2]

$\% \mathrm{M}=1.4286 \% \mathrm{R}-42.86 \quad$ (asume error $0,5 \%$ )

c.From step b, calculate the $\% \mathrm{Fe}$ met,

d.Once the metallic Fe is known, proceed to calculate the (dFe/dt) at a $30 \%$ reduction from the new curve $\% \mathrm{Fe}$ met vs. time. As an approximate value, it can be calculated as in equation 8

$(\mathrm{dFe} / \mathrm{dt})$ at $30 \% \mathrm{R}=0,83 *(\mathrm{~d} \% \mathrm{R} / \mathrm{dt}) 40 \% \mathrm{R}$

e.As the $\% \mathrm{~N} 2$ in the mixture is a known value, as well as the (dFe/dt) at $3 \%$, calculate the (\% Delta volume) can be calculated from equations 1 and 2 .

f.From step e, use equation 4 for the estimation of the \% volume increase (swelling index).

g.Once the $\%$ volume increase (swelling index) is calculated, is then possible to estimate the $\%$ nitrogen dissolved using equation 5 .

\section{A.Example of calculation}

The initial ore composition is assumed 
a. $\% \mathrm{Fe}$ total $65.5, \% \mathrm{FeO} 0.45$, which gives $28.09 \% \mathrm{O} 2$, reduced to give a $\% \mathrm{Fe}$ total of 80.58 .

b.Meaning a \%R of 66.6 .

c.The metallization degree is obtained through equation 6 , obtaining a value for $\% \mathrm{M}$ of 51.8 .

d.The basic mass balance gives the following complete analysis as $\mathrm{Fe}$ met.is $41.77 \%, \mathrm{Fe}+2$ is $35.85 \%$ and $\mathrm{Fe}+3$ of $2.96 \%$.

e.From the laboratory reducibility test curve, both the rate of reduction $(\mathrm{d} \% \mathrm{R} / \mathrm{dT}) 40 \%$ and the rate of metallization $(\mathrm{d} \% \mathrm{M} / \mathrm{dt}) 30 \%$ can be obtained as $5.88 \% \mathrm{Fe} / \mathrm{min}$.

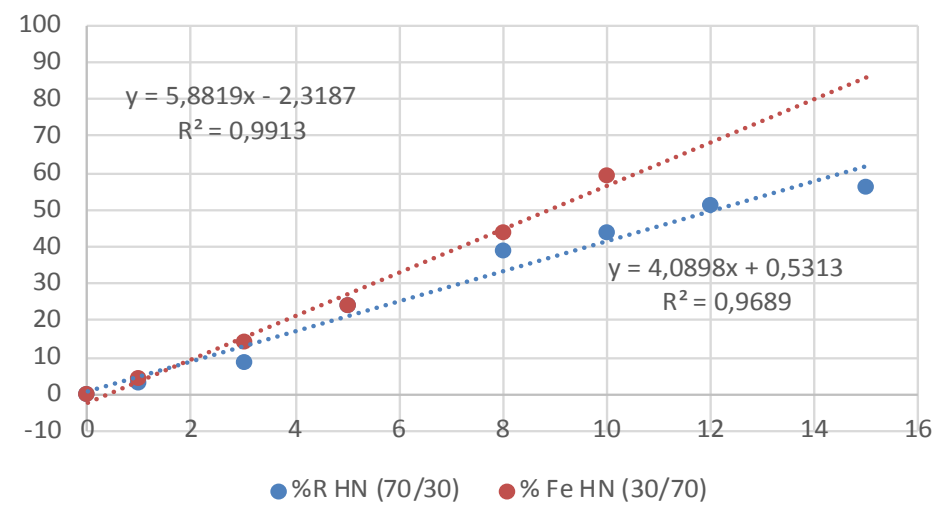

Fig. 6. Metallic iron formation(dFe/dt) $30 \%$ versus the reduction time for gas reduction with $3 \% \mathrm{H} 2 / 70 \%$ N2.

\section{B.The \%volume increase (Swelling Index)}

The volume increase is obtained from Fig.5 and equation 4, obtaining the value of $49.7 \%$.

For the obtained \%volume increase, the expected $[\% \mathrm{~N}]$ in equilibrium with iron is in the order of $0.02 \%+/-5 \%$ calculation accumulative error at the degree reduction considered.

The $\%$ nitrogen dissolved could be used for calculation of the stresses action for the lattice volume distortion.

\section{V.Results discussion}

The empirical relationships found between the rate of metallization (sM/dt) at $30 \%$ reduction, the swelling index (\%Volume), and the dissolved nitrogen in iron $[\mathrm{N}]$ in reduced samples, provides a useful tool in developing a mathematical model enabling to estimate the nitrogen absorption in the fresh iron produced during the reduction of iron ore samples. and therefore its effect on the swelling mechanism to be deduced from a single weight loss determination

Because of a limited data source on the nitrogen content in direct reduced iron, it is believed that it can be used for the assessment of more reliable measurement of the swelling mechanism of small scale laboratory swelling measurements during thermogravimetric swelling experiments and assessment.

With the estimation of the dissolved nitrogen, it is also possible to calculate the stresses on the reduced iron sample by the desorption of molecular gas during the cooling of the samples which has been overlooked in the measured swelling index according to the approved standard.

\section{REFERENCES}

[1]M. Kumar, B. Himanshu \& S. Kumar. "Reduction and Swelling of Fired Hematite Iron Ore Pellets by Noncoking Coal Fines for Application in Sponge Ironmaking". Mineral Processing and Extractive Metallurgy Review - MINER PROCESS EXTR METALL REV. 34. 10.1080/08827508.2012.656776. 2012.

[2]I. Mikko, M. Olli, A. Tuomas, V. Ville-Valtteri, K. Jari, P. Timo \& F. Timo. "Dynamic and Isothermal Reduction 
Swelling Behaviour of Olivine and Acid Iron Ore Pellets under Simulated Blast Furnace Shaft Conditions". ISIJ International. 52. 1257-1265. 10.2355/isijinternational.52.1257. 2012.

[3]M. Kumar. "Study of reduction kinectics of iron ore pellets by noncoking coal". Thesis of Master. National Institute of technology, Rourkela. 2009

[4]O. Dam. "The Influence of Nitrogen on the Swelling Mechanism of Iron Oxides During Reduction". PhD Thesis .Univ. of London. 1983.

[5]O. Dam and J. Jeffes. "Model for the Assessment of Chemical Composition of reduced iron ores from single measurements". Ironmaking and Steelmaking Journal. Vol. 14, N`5. 1987.

[6]O. Dam. "Efecto de la descomposición de gas de amoniaco (NH3) sobre el hinchamiento de óxidos de hierro durante reducción”. UCT Journal. Vol 100, 24. May 2020

[7]R. Agarwal and S. Hembram. "To Study the Reduction and Swelling Behavior Iron Ore Pellets". BSc. Department of Metallurgical and Materials Engineering National Institute Of Technology, Rourkela. May 2013

[8]Z. Chen, C. Zeilstra, J. Van der Stel , J. Sietsma \& Y. Yang. "Review and data evaluation for high-temperature reduction of iron oxide particles in suspension”. Ironmaking \& Steelmaking. Vol. 47. ํ⒎ pp. 741-747. 2019. 